\title{
Towards fair local outcomes in adaptation to sea-level rise
}

\begin{abstract}
Arguments that fairness should be a guiding principle of climate change adaptation have been primarily concerned with distributive and procedural aspects of fairness, with far less attention paid to the temporal, spatial and interactional dimensions of fairness. This paper presents the results of a study that sought to understand the multiple dimensions of fairness of adaptation strategies that exist or can be developed to deal with sea-level rise. The study focused on five small communities along the south-east coast of Australia-Lakes Entrance, Seaspray, Port Albert, McLoughlins Beach and Manns Beach. Interviews were conducted with residents of the local communities to examine perceptions of current adaptation policies and their social impacts. A questionnaire was used to develop a nuanced understanding of the types of people living in these communities and their everyday lives, practices, and relationships. This enabled us to identify a range of non-material social impacts that may occur as a result of sea-level rise. Finally, focus groups were used to obtain community perspectives on the fairness of a range of potential future adaptation strategies. Together, these methods revealed that adaptation to sea-level rise is likely to affect some groups in the community significantly more than others, and in ways that will fundamentally change the nature of living in these communities. Understanding nuances in the social values of communities reveals how policies can be adapted to provide fairer outcomes for all community members through processes that create the time and space required to establish long-term working relationships between communities and government.
\end{abstract}

Keywords climate change, climate justice, values, policy

\section{Introduction}

It has been repeatedly argued that climate change involves questions of fairness ${ }^{1}$ (e.g. Adger et al. 2006; Shue 1992) for two main reasons. First, the consequences of climate change involve redistribution of the timing and intensity of environmental processes, such as natural hazards and changes in mean sea levels, with significant and unequal repercussions for local, regional and national communities (Thomas and Twyman 2005; Fritze and Wiseman 2009).

\footnotetext{
${ }^{1}$ We follow Grasso's (2007) definitions of fairness and justice. Justice principles are those that exist independently of any process of judgment. Fairness relates to individual's perceptions arising from a judgment process. We are primarily concerned with residents' perceptions and thus preferentially use the term 'fairness'.
} 
Second, the people, communities, and countries that are most responsible for causing climate change do not usually experience the greatest impacts (Dow et al. 2006). Addressing climate change therefore involves attributing responsibility for the creation of the problem and addressing the resulting consequences (Grubb 1995). The United Nations Framework Convention on Climate Change has ensured that such fairness issues are central to climate change politics by holding countries accountable based on their differentiated responsibilities and respective capabilities (Grubb 1995; Thomas and Twyman 2005).

To date the majority of climate justice research has focused on attributing responsibility for greenhouse gas emissions at an international scale (Fritze and Wiseman 2009). A plethora of studies have applied various conceptualisations of justice to determine responsibility for existing greenhouse gas concentrations and the associated burden for ongoing mitigation and adaptation efforts internationally (e.g. Grubb 1995; Roberts and Parks 2010). Beyond this focus on the international dimensions of climate justice, little attention has been given to questions of fairness with respect to local impacts and adaptation responses (Adger et al. 2006).

Yet understanding fairness at local scales is important. Indeed it is becoming clear that adaptation plans at the local level are already impacting local communities. For example, in Australia, local governments are being required to plan for sea-level rise (SLR) now. The ability for coastal residents to purchase and develop land is being curbed by changes to local planning instruments (Macintosh 2012). There has been little, if any, consideration of the social impacts of these policies and the extent to which they are considered fair by local communities.

An emerging body of research seeks to understand the procedural and/or distributive fairness implications of adaptation to climate change. Almost all of the empirical research in this field has been concerned with developing countries (e.g. Barnett 2009; Huq and Khan 2006). The handful of empirical studies conducted in developed countries focus on climate adaptation in general (e.g. Novaczek et al. 2011; Wolf et al. 2013) rather than adaptation to specific environmental changes, such as SLR. The research described here is distinct and significant because it focuses on the impacts of adaptation to SLR on five coastal communities in a developed country-Australia. It goes beyond simply identifying vulnerabilities, adaptive capacity, and possible injustices, as has been the focus of past investigations into fair adaptation (Schlosberg and Collins 2014). In this paper we explain, with evidence, the multiple dimensions of fairness of actual and planned adaptation, as perceived by residents of communities at risk of SLR. The next section will explain the way 
fairness has previously been conceptualised in climate justice research and introduce other conceptualisations of fairness that may be useful.

\section{Principles of fairness for local climate adaptation}

'Putting the most vulnerable first' is the overarching fairness principle most commonly associated with local adaptation studies (Barnett 2009; Burton et al. 2002). It is also one of the four principles that Paavola and Adger (2006) proposed should be adopted to achieve fair adaptation to climate change. This principle has wide appeal because it provides an avenue for redressing existing, and preventing future, inequalities. According to Rawls (1999) the least advantaged need to be prioritised if we are to achieve equality. The attention given to this principle reflects the bias in adaptation research towards distributive fairness concerns (Schlosberg and Collins 2014). The most vulnerable are also unlikely to be able to command the attention of decision makers and so a focus on these groups can also lead to procedurally fair adaptation.

While it is important to focus on the most vulnerable globally and nationally, there is rarely sufficient information to identify the specific groups and local places at highest risk (Dow et al. 2006). Even if such information were available, focusing only on the 'most vulnerable' groups within a community reproduces conventional ideas of disadvantage (Stanley 2009) and can result in other vulnerabilities being overlooked. Stanley (2009) argues that we need to go beyond acknowledging differences to identifying and recognising diversity. Understanding diversity requires conceptions of environmental fairness beyond those that are explicitly or implicitly distributional at their core (Forsyth 2013). As will be seen throughout this paper, we find it useful to understand the diversity of social values that exist within a community, not just those of the 'most vulnerable,' and accommodate a variety of conceptions of fairness in adaptation research and policy.

Distributive fairness is concerned with the allocation of "wealth, rights, honours and other benefits, and duties" (Cullen, 1992, p. 15 cited in Grasso 2007, p. 5). In the context of climate adaptation it is usually defined as the distribution of the benefits and adverse effects of climate change (e.g. Müller 2001; Paavola and Adger 2006). Focusing on distributive fairness helps to identify potential 'winners' and 'losers' of environmental changes associated with climate change, as well as adaptation policies. This knowledge can be used to design future adaptation policies that address, or redress, inequalities (Adger et al. 2006). However, the 
successful design or redesign of such policies in the absence of knowledge about other dimensions of fairness is unlikely (Paavola et al. 2006).

Procedural fairness is the other major conceptualisation of fairness that appears in studies of climate adaptation. Procedural fairness is concerned with the processes - how and by whom-decisions on adaptive responses are made (Thomas and Twyman 2005). It is concerned with issues of recognition, participation, representation and distribution of power with a view to achieving empowerment and legitimacy (Adger and Nelson 2010; Paavola et al. 2006; Thomas and Twyman 2005). While fair adaptation processes are usually seen as ends in themselves, outcomes derived through fair processes are also usually perceived as fairer (Paavola and Adger 2006). Thus procedural and distributive fairness are intimately intertwined.

While the adaptation literature is preoccupied with distributive and procedural fairness, three other types of fairness discussed within the broader justice literature are relevant to the development and implementation of adaptation strategies. These are interactional, spatial, and temporal fairness (Bies 2005; Lukasiewicz et al. 2013). Interactional fairness refers to individuals' perceptions of the treatment they experience during the explanation and representation of decisions and procedures (Usmani and Jamal 2013). It is conceptually distinct from procedural fairness because it is concerned with interpersonal interactions rather than the formal structural aspects of decision-making processes (Lukasiewicz et al. 2013). There are two sub-types of interactional fairness: interpersonal — being treated with dignity and respect; and informational—-being provided with sufficient information in a timely manner (Usmani and Jamal 2013). Interactional fairness has been found to be important for natural resource management decision-making. For example, local opposition to a water redistribution project in south-eastern Australia was exacerbated by the perceived disdainful treatment of affected communities by decision-makers (Fischer et al. 2012). This is consistent with Lukasiewicz et al. (2013), who found that decision-makers with water management responsibilities overlook the importance of interactive justice for achieving water reform. Likewise in the context of climate adaptation, an individual's personal experiences with decision makers and key community representatives will influence their perceptions of interactional fairness.

Spatial and temporal fairness cut across distributive, procedural and interactional fairness, although most often they are associated with distributive fairness. Spatial justice involves "the fair distribution in space of socially valued resources and the opportunities to utilise them" (Usmani and Jamal 2013, p. 360). Temporal justice has two dimensions, the first is 
"distribution of time (or, more precisely, discretionary control over one's time) among people within the same timeslice" (Goodin 2010, p. 1) and the second is "justice through time" (Hockett 2009, p. 1149).

In the climate adaptation and environmental justice literature there are implicit assumptions about the need for temporal and spatial fairness in decision-making processes. Paavola and Adger (2006) indicate that the timing of adaptation responses with respect to climate change impacts is a question of justice. Similarly, Burton et al. (2002) argue that it is necessary for policy analysis and development to be taken at an appropriate pace to prevent making "wrong" decisions. There is also discussion about how to achieve intergenerational fairness (Adger and Nelson 2010). With respect to spatial fairness, Walker (2009) argues for the need to "enabl[e] access to spaces... that have previously been restricted...[because] a lack of procedural justice is intimately wrapped up with a closed geography of information, access and power" (p. 37). Clearly the conceptualisation and operationalisation of spatial and temporal fairness within climate adaptation is in its infancy, and so, this study deliberately assessed whether these types of fairness help explain the development of fair local adaptation processes.

\section{Understanding the role of fairness in adaptation to sea-level rise}

A range of methods were used to investigate the fairness of adaptation to SLR in Lakes Entrance, Seaspray, Port Albert, McLoughlins Beach and Manns Beach in East Gippsland, Australia (Figure 1). A detailed explanation of the full suite of methods used is provided in **** et al. (2014). The results and discussion presented here draw on semi-structured interviews (Section 3.1.1), surveys (Section 3.1.2), and focus groups (Section 3.3) conducted in the five communities. The methods and results are discussed together because of the exploratory nature of this research; the results and analysis from each stage of the research informed the next stage.

Fig. 1 Study sites along the East Gippsland coast, Victoria, Australia

\subsection{Conceptualising and operationalising social values}

A small, emerging body of climate research has argued for a values-based approach to adaptation that focuses on sustaining the things that people value about the places in which 
they live (Barnett 2010; O'Brien and Wolf 2010). It has been proposed that incorporating such values into adaptation strategies should ensure that the process and outcomes of adaptation are more equitable, inclusive, and legitimate (Adger et al. 2013; Novaczek et al. 2011; O'Brien and Wolf 2010). Thus, understanding values is seen to present a useful approach to evaluating the distributive and procedural fairness of adaptation options.

Values can also be related to the concepts of interactional, spatial and temporal fairness. Lukasiewicz et al. (2013) argue that interactional fairness requires government officials to explicitly consider the values of communities; it is only by genuinely considering such values that respect and recognition in interpersonal interactions can be achieved. The concepts of spatial and temporal fairness are also inextricably linked to values because they are about achieving a fair distribution of socially valued resources through space and time (Usmani and Jamal 2013). One of the contributions of this paper is to explain the extent to which concepts of fairness are linked to values in the context of climate adaptation.

Although there are growing calls for values-based approaches to adaptation, the concept of values is poorly conceptualised; few definitions are provided and the term 'values' is used to refer to a range of phenomena. We conducted a review of five bodies of research on social values - human geography, psychology, climate adaptation, social impact assessment, and decision analysis - to determine how to conceptualise and operationalise social values for the purposes of assessing the fairness of adaptation to SLR. From this analysis we developed the concept of 'lived values,' which are 'valuations that individuals make, in isolation or as part of a group, about what is important in their lives and the places they live... [and which] may be articulated verbally or expressed through everyday activities" (**** et al., 2013, p. 49). There are five types of lived values: health—such as access to welfare and a healthy lifestyle; safety—-such as financial security and access to services; belongingness — such as social interactions and sense of belonging; esteem—such as being respected and having efficacy; and self-actualisation — such as freedom and work-life balance. This conceptualisation underpinned our empirical research.

\subsubsection{Exploring lived values and community responses to adaptation policies}

Once we had elaborated the concept of lived values we conducted semi-structured interviews with individuals in the five communities. The purpose was to explore how to operationalise the lived values concept and understand current perceptions of adaptation policies and their effects on communities. Throughout April and May 2012 thirty-five interviews were 
conducted; eighteen in Lakes Entrance, five in Seaspray, and four each in Port Albert, Manns Beach and McLoughlins Beach. We aimed to speak to diverse residents to capture a wide range of lived values and flooding experiences. As such, potential participants were recruited by: calling community groups listed on the relevant local government websites; approaching business owners who operate in flood prone parts of the towns; approaching people utilising the community halls at the times visits were made to the communities; and by snowballing. During the interviews we asked residents about their reasons for moving to and living in their town; what they like and dislike about their town; what they would like to see changed; the activities they participate in, where these activities take place and with whom; and their experiences of coastal flooding. All the interviews were digitally recorded and transcribed, and then thematically analysed in NVivo to identify the lived values and dimensions of fairness that were important to participants.

A total of 136 distinct lived values were identified from these interviews, although each interviewee only held a subset of values and some values were place-specific; only 30 of the lived values were identified in all five communities (Online Resource 1). Analysis of the interview transcripts indicated that individuals' lived values differed according to their life characteristics. Specifically whether residents were employed or retired; owned a business; were actively engaged in the community; or had a long-term connection to the area.

The interviews also elicited useful information about people's understandings of adaptation to SLR. Analysis of the interviews showed that while many residents acknowledge that the sporadic coastal flooding they experience at present causes inconveniences, none consider it to be a major problem. Instead, interviewees indicated that SLR adaptation policies are of greater concern, with five dimensions of fairness identifiable in their discussions about adaptation (Table 1). Distributively, there is insufficient consideration of the values that are being impacted by these policies; they wanted to see compensation for these losses.

Procedurally and interactively, residents felt that either they were not being consulted or, if they were being consulted, that they were not treated with respect. Spatially, adaptation efforts have been concentrated in some places more than others, resulting in a greater burden on the study communities than suburbs in Melbourne that are also at risk. Temporally, the adaptation policies have not been implemented over reasonable timeframes; the burden is on current generations.

Table 1 Illustrative examples of interviewees' perceptions of fairness of adaptation to SLR 
3.2.2 Understanding the diversity of lived values that exist within communities

Based on the theory of lived values that was developed, and the interviews to elicit the range of lived values empirically, a survey was developed and administered in order to develop a more detailed and comprehensive understanding of the types of people who live in the five communities and their lived values. During September and October 2012 a telephone survey was conducted in Lakes Entrance and mail ${ }^{2}$ surveys were conducted in the four smaller communities. The telephone survey was administered by an independent research consultancy firm, using a publicly available telephone list. The mail-out surveys and follow-up postcards (as per Dillman, 2007) were hand delivered to every home in Manns Beach, McLoughlins Beach and Seaspray, and were placed in every post office box in Port Albert. Approximately $8.7 \%$ of all households (with permanent or temporary residents) in the five communities responded to the surveys; 199 households in Lakes Entrance and 134 households across the four smaller communities.

Respondents identified 50 distinct things that are most important to them about living in each of the communities (Online Resource 2). Being close to water and peace and quiet were the only lived values that were frequently mentioned in all five communities. This corresponds closely to the lived values that respondents rated as very important in response to a pre-determined list of lived values (Online Resource 3). In all five communities, the natural environment was consistently rated as one of the five most important lived values. In the four small communities, being close to water and peacefulness were always in the top five lived values. There was less consistent importance attached to the remaining lived values listed, both within and across communities.

Cluster analysis was used to group respondents according to their life characteristics. Statistically significant differences between the lived values of the groups were then identified. There were eight groups of residents identified in Lakes Entrance and five groups of residents identified in the remaining communities. Each group of residents had a unique set of lived values that they rated as being very important, activities that they engaged in, and relationships that they maintained. Detailed descriptions of the types of residents identified in the five communities are provided in $* * * *$ et al. (2014).

\footnotetext{
${ }^{2}$ Mail surveys were deemed to be more appropriate in the smaller communities given the large number of second home owners who irregularly live in these communities, and the difficulty of obtaining publically available phone numbers for the households in these locations.
} 
Comparing the lived values of groups within the communities against possible adaptation options provides insights into distributive impacts. In Lakes Entrance, groups who were more likely to go to the beach, and thus would be more affected by hard coastal protection, were the same groups who were concerned about the lack of entertainment options and activities for youth. Conversely, groups who use the beach less, such as retirees, were more likely to need better access to medical services and public transport, which would be hampered by relocation of the town. Such knowledge not only provides insights into which groups will be more affected by various adaptation options but also indicates the trade-offs that could be made to compensate for these negative social impacts.

\subsection{Community evaluation of future adaptation options}

If lived values are to form the basis of future adaptation policies then community involvement will be essential; residents are best placed to evaluate whether their lived values will be accommodated by future plans, and the possible trade-offs for the loss of some of those lived values. To this end focus groups were run in each of the five communities to understand how residents are likely to perceive future adaptation policies.

During March and April 2013 eight focus groups were run across the five communities with people who had previously participated in the interviews or surveys. Three focus groups were run in Lakes Entrance with a total of 14 participants - four or five residents in each group. Five focus groups were run across the four smaller communities (two were held in McLoughlins Beach due to the large number of people who agreed to be involved) with a total of 35 participants (five to eight residents attended each). During the focus groups participants were asked about the things they value most about living in their towns as well as their experiences of flooding. They were presented with two hypothetical flooding scenarios, which were developed in consultation with experts on local environmental processes. Participants were asked to discuss how the scenarios would impact them and others, whether they would expect the government to act, and in what ways. All the focus groups were digitally recorded and transcribed, and then thematically analysed in NVivo to identify the lived values and dimensions of fairness that were identified as being important by participants.

The focus group discussions regarding lived values were consistent with the findings of the interviews and surveys. Indeed, it was possible to determine which group of residents from 
the cluster analysis participants belonged to based on their life characteristics and lived values. Similarly, the discussions regarding current experiences of flooding mirrored those raised during the interviews. Focus group participants described some of the ways in which their activities, homes and businesses had been affected but downplayed the significance of these impacts.

When considering two hypothetical flooding scenarios participants in six of the eight focus groups (Port Albert and one McLoughlins Beach group were the exceptions) acknowledged that they would be more concerned about flooding if it occurred more frequently. For example, if low-level (1-in-10 year) or high-level (1-in-100 year) flood events were to occur at least annually then the communities would want to see prompt government action.

There were five types of action that communities expected governments to engage in. First, greater investment in maintenance of existing facilities and infrastructure, particularly drainage. Second, investigation and investment in engineering solutions, such as sea walls, levees, raised roads, and better storm water drainage. These first two actions indicate that protecting and enhancing existing lived values primary concerns. Third, development of projects that would provide the towns with new identities, such as investing in renewable energy or new industries. Fourth, introduction of planning regulations, such as raised floor heights. Fifth, establishment of financial incentives for developers to build housing and facilities, if the need to relocate was established. Financial compensation would also need to be provided for people to relocate their homes and business premises. Across all of these actions communities expected governments to be clear, consistent and strong in their decision-making. They wanted to see consensus among the various levels and branches of government that SLR is a problem and agreement about what should be done. They also wanted to see locally-tailored solutions that incorporate the different lived values and risks being faced by each community.

In discussing the five actions, participants were adamant that there needed to be better communication between governments and communities about the planning and implementation of adaptation options (Table 2). Most participants expected to be involved in discussions about the options available to their community; they explicitly expressed the need for greater transparency in decision-making as well as greater recognition and inclusion of local knowledge. Their key practical suggestion for how this could be achieved was through the establishment of a community-liaison individual, or organisation, employed for the longterm so that community members could build a working relationship with government. The community liaison individual/organisation was seen to be necessary because of the difficulty 
the community currently faces in engaging with the multitude of government departments that have input into adaptation decisions. Some focus group participants also called for the establishment of a community consultation group through which government departments could seek local input. Overall, participants expected to be provided with more timely and comprehensive information about government decision-making.

Table 2 Illustrative examples of focus group participants' perceptions of fairness of adaptation to SLR

\section{Developing fair adaptation policies}

Residents' concerns about the fairness of adaptation to SLR are multifaceted. At the most general level the results indicate that understanding the diversity of lived values that exists within communities provides a means for informing and evaluating the distributive fairness of adaptation policies. Beyond this, discussions with communities indicate that they are concerned about the procedural, interactional, temporal and spatial fairness of adaptation policies (Tables 1 and 2). The way communities discussed these types of fairness was mostly consistent with existing conceptualisations but suggested that some new interpretations are required.

The lived values concept provides fundamental information for informing fair adaptation outcomes that are not simply based on putting the most vulnerable first. If decision makers have detailed information about the most important lived values for the community as a whole as well as groups within the community then it is possible to develop policies that are distributively fair. This is because such knowledge enables policy makers to evaluate the effects of policies on the lived values of different groups within the community and the extent to which some groups' lived values conflict with those of other groups. While the lived values approach does not stipulate whose values should be prioritised, it brings to light the multiple value conflicts that need to be resolved, and makes transparent processes and outcomes more likely. O'Brien and Wolf (2010), in their explanation of values-based approaches to adaptation, suggest that one way to reconcile such value conflicts is to prioritise adaptive responses that benefit the largest interpretation of 'we' that is possible and that enhance the capacity of individuals to respond to their environmental, social and human rights in present and future generations. 
When local residents discussed adaptation to SLR they were not only concerned about the impacts of policies on their ability to continue going about their everyday lives, they were also concerned about the process through which adaptation decisions are made and by whom. They expected local residents to be actively involved in the process and that local knowledge would be recognised; they did not believe that government departments based in Melbourne have sufficient local knowledge to make adaptation decisions. This suggests that they were concerned with issues of recognition, participation, representation, and distribution of power between local communities and various tiers of government, which provides empirical evidence for claims made about the importance of procedural fairness for climate adaptation (Adger and Nelson 2010; Paavola et al. 2006; Thomas and Twyman 2005).

Most residents also expressed a desire to have long-term working relationships with government staff involved in adaptation, suggesting that interactional fairness is important. Consistent with past research, there was evidence of two sub-types of interactional fairness (Bies 2005; Lukasiewicz et al. 2013). Interpersonal fairness was evident in residents' expectations that they should be treated with dignity and respect in their interactions with government; they wanted governments to engage directly with them regarding matters that affect their community, and particularly issues that could stigmatise their community, like flooding and SLR. Informational fairness was evident in residents' expectations that government should provide them with information about SLR projections, the risks presented by SLR to their community, and the possible adaptation options being considered. They expected decision-making processes to be transparent and to provide residents with comprehensive information. The recommendations regarding the establishment of community liaison staff as well as community consultation groups points to the significance of interactional fairness for adaptation, and provides concrete suggestions for how to ensure such fairness can be achieved.

Cutting across distributive, procedural and interactional fairness were concerns regarding temporal fairness. Many residents were concerned about the timing of adaptation policies relative to the incidence of SLR impacts. For example, many believed it is unreasonable to expect residents to invest in raising floor heights to accommodate sea-levels that are not expected to eventuate for 90 years. Here temporal fairness is associated with intergenerational distributive fairness (Adger and Nelson 2010); residents do not feel that they should bear all the burden of adaptation costs. Residents also indicated that temporal fairness is related to procedural and informational fairness. Residents expect adaptation policies to be developed over 'reasonable' periods of time and provide residents with information in a timely manner, 
thereby enabling the community to be involved in the process and have time to adapt. This suggests that temporal fairness in adaptation decision-making processes is about empowering local communities to take action at their own pace. Such short-term temporal fairness has not been adequately conceptualised in the literature; the focus to date has been on achieving equity in particular moments in time - time slices - or time that spans generations.

Spatial fairness was the other principle that was evident in residents' discussions regarding adaptation. Residents wanted assurances that their towns were not being forced to adapt to SLR when other at risk communities are not. This element of spatial fairness has not previously been discussed in the fields of organisational management (Usmani and Jamal 2013) or environmental justice (Walker 2009) and suggests that the definition of spatial fairness may need to be expanded to cover broader distributive concerns. The other element of spatial justice that residents discussed related to adaptation decision-making. They currently feel excluded from the development of adaptation policies and would like to see greater levels of community engagement. This is consistent with Walker's (2009) argument that there is a need to provide access to political spaces that have previously been restricted. Although Walker (2009) was concerned with environmental justice more generally, it is evident that this conception of spatial justice is also relevant to climate justice specifically.

\section{Conclusions}

It has previously been argued that a values-based approach to climate adaptation should result in fairer and more legitimate adaptation practices. This study has shown that the 'lived values' concept provides one way of conceptualising social values for the purposes of evaluating the fairness of climate adaptation. The benefit of understanding the importance that residents attach to the attributes of places in which they live, their everyday activities, and social interactions is that it provides insights into the distributive fairness of adaptation policies, which is likely to have flow on effects to the perceived legitimacy of decisions.

Understanding the lived values that residents believe are missing is also useful. Residents indicated that they are most frustrated with local government decision-making. Not only do they want assurances that their lived values are being considered during the development of adaptation policies, they are also concerned with procedural fairness. In particular, residents were concerned about the ways in which communities are engaged in adaptation decisionmaking, particularly: the inclusion of local knowledge into planning (procedural fairness); the extent to which they are provided with information about possible adaptation options 
(informational fairness); the way they are treated by staff in government agencies (interactional fairness); the timing and pace of decisions relative to climate impacts (temporal fairness); and access to policy making spaces that have previously been unavailable to them (spatial fairness).

Although the focus of this study was on five small communities at risk of SLR in Australia it is evident that the approach taken here could be equally applied to other communities facing other climate change risks. In translating this approach to other communities, consideration needs to be given to the geographical spread of the community of interest relative to the risk being posed. In the small communities under investigation here, SLR poses some level of risk to all community members. In other places, such as sprawling cities, the nature of the risk may vary dramatically, making questions about 'whose values count?' even more salient.

The empirical results provided here confirm normative arguments that distributive and procedural fairness are important for climate adaptation. A values-based approach provides practical insights for achieving distributive fairness and reveals a suite of other fairness concerns that residents believe are currently lacking. Clearly, future research into climate justice needs to further conceptualise and operationalise the concepts of interactional, temporal and spatial fairness to ensure that climate adaptation addresses all of these justice dimensions.

\section{Acknowledgements}

**** We would like to acknowledge the support provided by these agencies. We would also like to thank all the people who participated in our research. 


\section{References}

Adger N, Brown K, Barnett J, Marshall N, O'Brien KL (2013) Cultural dimensions of climate change impacts and adaptation. Nature Climate Change 3:112-117

Adger WN, Nelson DR (2010) Fair decision making in a new climate of risk. In: O'Brien KL, St. Clair AL, Kristoffersen B (eds) Climate Change, Ethics and Human Security. Cambridge University Press, Cambridge, pp 83-94

Adger WN, Paavola J, Huq S (2006) Toward justice in adaptation to climate change. In: Adger WN, Paavola J, Huq S, Mace MJ (eds) Fairness in adaptation to climate change. Massachusetts Institute of Technology, Cambridge, MA, pp 1-19

Barnett J (2009) Justice and adaptation to climate change. In: Moss J (ed) Climate Change and Social Justice. Melbourne University Press, Melbourne, pp 131-143

Barnett J (2010) Adapting to climate change: three key challenges for research and policy--an editorial essay. WIREs Climate Change 1 (May/June):314-317

Bies RJ (2005) Are procedural justice and interactional justice conceptually distinct? In: Greenberg J, Colquitt JA (eds) Handbook of Organizational Justice. Lawrence Erlbaum Associates, Mahwah, NJ, pp 85-112

Burton I, Huq S, Lim B, Pilifosova O, Schipper EL (2002) From Impacts Assessment to Adaptation Priorities: the Shaping of Adaptation Policy. Climate Policy 2:145-159

Dillman DA (2007) Mail and Internet Surveys: The Tailored Design Method (2 ${ }^{\text {nd }}$ Edition). John Wiley \& Sons, New Jersey.

Dow K, Kasperson RE, Bohn M (2006) Exploring the social justice implications of adaptation and vulnerability. In: Adger WN, Paavola J, Huq S, Mace MJ (eds) Fairness in adaptation to climate change. Massachusetts Institute of Technology Press, Cambridge, MA, pp 79-96

Fischer J, Dyball R, Fazey I, Gross C, Dovers S, Ehrlich PR, Brulle RJ, Christensen C, Borden RJ (2012) Human behavior and sustainability. Frontiers in Ecology and the Environment 10 (3):153-160. doi:10.1890/110079

Forsyth T (2013) Climate justice is not just ice. Geoforum. doi:http://dx.doi.org/10.1016/j.geoforum.2012.12.008

Fritze J, Wiseman J (2009) Climate justice: key debates, goals and strategies. In: Moss J (ed) Climate Change and Social Justice. Melbourne University Press, Melbourne, pp 187211

Goodin RE (2010) Temporal justice. Journal of Social Policy 39 (1):1-16 
Grasso M (2007) A normative ethical framework in climate change. Climatic Change 81 (34):223-246

Grubb M (1995) Seeking fair weather: ethics and the international debate on climate change. International Affairs 71 (3):463-496

Hockett R (2009) Justice in time. The George Washington International Law Review 77 (5/6):1135-1172

Huq S, Khan MR (2006) Equity in National Adaptation Programs of Action (NAPAs): The Case of Bangladesh. In: Adger WN, Paavola J, Huq S, Mace MJ (eds) Fairness in adaptation to climate change. Massachusetts Institute of Technology Press, Cambridge, MA, pp 181-200

Lukasiewicz A, Bowmer K, Syme GJ, Davidson P (2013) Assessing Government Intentions for Australian Water Reform Using a Social Justice Framework. Society \& Natural Resources 26 (11):1314-1329. doi:10.1080/08941920.2013.791903

Macintosh A (2012) Coastal adaptation planning: A case study on Victoria, Australia. ANU Centre for Climate Law and Policy, Canberra

Müller B (2001) Varieties of distributive justice in climate change. Climatic Change 48 (2):273-288

Novaczek I, MacFadyen J, Bardati D, MacEachern K (2011) Social and cultural values mapping as a decision-support tool for climate change adaptation. The Institute of Island Studies, University of Prince Edward Island, Charlottetown, Canada

O'Brien KL, Wolf J (2010) A values-based approach to vulnerability and adaptation to climate change. Wiley Interdisciplinary Reviews: Climate Change 1 (2):232-242

Paavola J, Adger N (2006) Fair adaptation to climate change. Ecological Economics 56:594609

Paavola J, Adger WN, Huq S (2006) Multifaceted justice in adaptation to climate change. In: Adger WN, Paavola J, Huq S, Mace MJ (eds) Fairness in adaptation to climate change. Massachusetts Institute of Technology Press, Cambridge, MA, pp 263-278

Rawls J (1999) A theory of justice. Belknap Press,

Roberts JT, Parks BC (2010) A "shared vision"? Why inequality should worry us. In: O'Brien KL, St. Clair AL, Kristoffersen B (eds) Climate Change, Ethics and Human Security. Cambridge University Press, Cambridge, pp 65-82

Schlosberg D, Collins LB (2014) From environmental to climate justice: climate change and the discourse of environmental justice. Wiley Interdisciplinary Reviews: Climate Change 5 (3):359-374. doi:10.1002/wcc.275 
Shue H (1992) The unavoidability of justice. In: Hurrell A, Kingsbury B (eds) The international politics of the environment. Oxford University Press, Oxford, pp 373397

Stanley A (2009) Just space or spatial justice? Difference, discource, and environmental justice. Local Environment: The International Journal of Justice and Sustainability 14 (10):999-1014

Thomas DSG, Twyman C (2005) Equity and justice in climate change adapatation amongst natural-resource-dependent societies. Global Environmental Change 15:115-124

Usmani S, Jamal S (2013) Impact of Distributive Justice, Procedural Justice, Interactional Justice, Temporal Justice, Spatial Justice on Job Satisfaction of Banking Employees. Review of Integrative Business and Economics Research 2 (1):351-383

Walker G (2009) Beyond distribution and proximity: Exploring the multiple spatialities of environmental justice. Antipode 41 (4):614-636

Wolf J, Allice I, Bell T (2013) Values, climate change, and implications for adaptation: Evidence from two communities in Labrador, Canada. Global Environmental Change 23:548-562 
Table 1 Illustrative examples of interviewees' perceptions of fairness of adaptation to SLR

\begin{tabular}{|c|c|}
\hline $\begin{array}{l}\text { Dimension } \\
\text { of fairness }\end{array}$ & Comments made by interviewees \\
\hline Distributive & $\begin{array}{l}\text { "There's a little bit of a discrepancy to what the council thinks we use or need and what we know } \\
\text { we need and use" (Manns Beach) } \\
\text { "There's absolutely no compensation for places like Lakes Entrance, and that's the sad part of it" } \\
\text { (Lakes Entrance) }\end{array}$ \\
\hline Procedural & $\begin{array}{l}\text { "It was a decision made without consultation with any of the fishermen concerned. It was } \\
\text { something that was pretty much just handed down, and we received this draft notice and realised } \\
\text { that this would put us out of business." (Port Albert) }\end{array}$ \\
\hline Interactional & $\begin{array}{l}\text { "I think [we need] a better relationship with council, a more authentic relationship where they're } \\
\text { listening and able to not give us political jargon as to why things can't be done, but rather an } \\
\text { honest reason." (Manns Beach) } \\
\text { "The problem, one of the biggest problems... [is] the respect for volunteers, it's really contempt } \\
\text { - local government treats you with contempt... You've only got so much energy and we'll [the } \\
\text { council] wear you down to the point where you won't bother us anymore" (McLoughlins Beach) }\end{array}$ \\
\hline Spatial & $\begin{array}{l}\text { "What we want to know is why isn't... Port Philip Bay [where Melbourne is located] being } \\
\text { treated the same as we've been treated?" (Lakes Entrance) } \\
\text { "The risks that face towns like Lakes Entrance, are no different to the risks that face St Kilda } \\
\text { esplanade [in Melbourne]" (Lakes Entrance) }\end{array}$ \\
\hline Temporal & $\begin{array}{l}\text { "You don't have to do it tomorrow you've got } 100 \text { years to do it, right. This is what we can't } \\
\text { understand, why bash a community to pieces when you've got } 100 \text { years to fix it?" (Lakes } \\
\text { Entrance) } \\
\text { "[They say McLoughlins Beach] will not get anything now because in } 2100 \text { it's going to be } 0.8 \\
\text { of a sea-level rise. Then down a bit further they say infrastructure is } 15 \text { to } 30 \text { years of } \\
\text { infrastructure life span... well let's put in the infrastructure today and in } 15 \text { or } 30 \text { year's time... } \\
\text { let's revisit and say, well there's been a change, now it's not appropriate. But we've got } 15 \text { years } \\
\text { of use of that infrastructure now before that occurs. But then they baulk at that and they go back } \\
\text { to their original thing" (McLoughlins Beach) }\end{array}$ \\
\hline
\end{tabular}


Table 2 Illustrative examples of focus group participants' perceptions of fairness of adaptation to SLR

\begin{tabular}{|c|c|}
\hline $\begin{array}{l}\text { Dimension } \\
\text { of fairness }\end{array}$ & Comments made by focus group participants \\
\hline Distributive & $\begin{array}{l}\text { "They jumped to the quick solution, which is to regulate the poor land owners and the property } \\
\text { owners into forcing their buildings upwards, which is such a silly solution when you think of the } \\
\text { costs. The costs on that surf shop must be horrendous - the extra costs there." (Lakes Entrance) } \\
\text { "I think that [SLR] it's a distraction. I think that the whole effort to sort of somehow come to } \\
\text { terms with climate change through what has been currently attempted in the last few years by } \\
\text { way of governance, is diverting resources away from the ability to be able to mitigate the effects } \\
\text { of the flooding, and all these things." (Lakes Entrance) }\end{array}$ \\
\hline Procedural & $\begin{array}{l}\text { "But the situation like this where you're talking about people's livelihood and their investment } \\
\text { and their wellbeing then it needs to be done properly and in consultation with the local } \\
\text { community, it has to be." (Port Albert) "I think it should be policy, whenever there's consultants } \\
\text { employed, there's a high input from local knowledge, because local knowledge can't - you can't } \\
\text { beat it." (Manns Beach) } \\
\text { "Maybe we need to form a group of people in this area that want to deal with this specifically } \\
\text { and so that people like **** could feel confident that they were being heard, but by local } \\
\text { people." (Lakes Entrance) }\end{array}$ \\
\hline Interactional & $\begin{array}{l}\text { Informational } \\
\text { "You'd like to see someone from government come down and say, okay, we're going to have a } \\
\text { town meeting and we're going to discuss this. If we don't get it right at least you know someone's } \\
\text { come down to have a chat to us." (Lakes Entrance) } \\
\text { "Communication: give us someone to talk to permanently... have one authority that's dealing } \\
\text { with this all the time. There's never a change in personnel, they all know what's happening. It's } \\
\text { not handball from one [government agency] to the other." (Lakes Entrance) } \\
\text { Interpersonal } \\
\text { "Someone who knows what they're doing and so you can come with your problems and know } \\
\text { you're going to have ears that are hearing you that have experienced what it's like here, and } \\
\text { they're going to fix something" (McLoughlins Beach) } \\
\text { "I mean if you've got a problem and you walk into the council, the first thing I feel that the } \\
\text { council think of me is: oh, here comes the enemy." (McLoughlins Beach) }\end{array}$ \\
\hline Spatial & $\begin{array}{l}\text { "There's no one recipe for a fix because each of the places are all different. So I think the system } \\
\text { has got to look at each place individually and to start some mechanisms in place now to prepare } \\
\text { for this so-called sea rise, rather than waiting until it happens." (Manns Beach) } \\
\text { "I think you've got to assess each place on its own merits according to the circumstances of the } \\
\text { time. You can't put a one size fits all - it doesn't - what's applicable here is not applicable at } \\
\text { Manns [Beach], is not applicable at Robby's [Robertsons Beach]" (McLoughlins Beach) }\end{array}$ \\
\hline Temporal & "You're sucking resources out of the community by forcing them to deal with a projected sea- \\
\hline
\end{tabular}


level rise by making them build higher basically, instead of enabling that community to deal with the flooding in a more direct way as it's happening now." (Lakes Entrance)

"I would like to see some action from government moneys and whatever, start to plan towards that now, rather than wait until closer to 2100." (Manns Beach" 


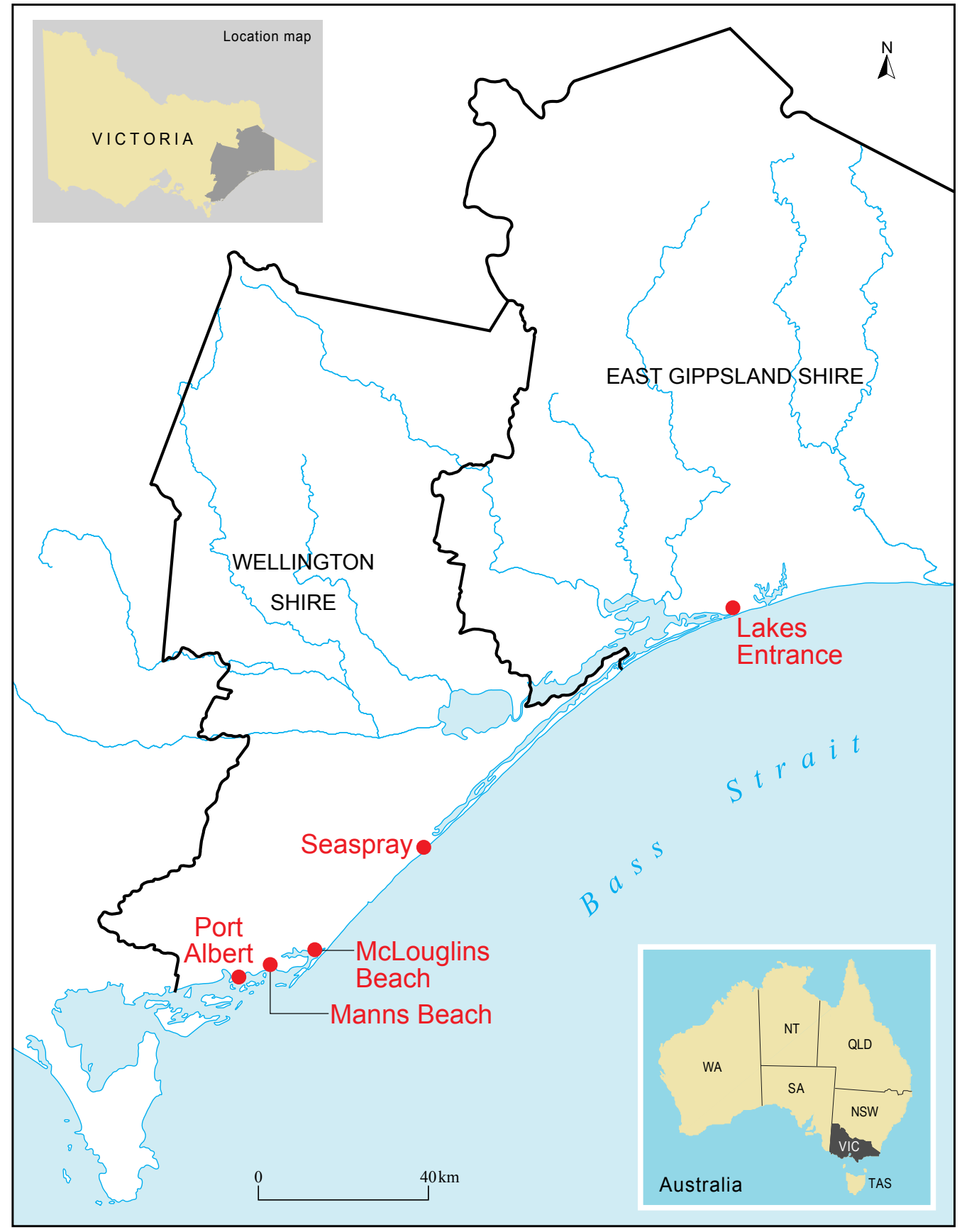




\section{University Library}

\section{- M M I N E R VA A gateway to Melbourne's research publications}

Minerva Access is the Institutional Repository of The University of Melbourne

Author/s:

Graham, S;Barnett, J;Fincher, R;Mortreux, C;Hurlimann, A

Title:

Towards fair local outcomes in adaptation to sea-level rise

Date:

2015-06-01

Citation:

Graham, S., Barnett, J., Fincher, R., Mortreux, C. \& Hurlimann, A. (2015). Towards fair local outcomes in adaptation to sea-level rise. CLIMATIC CHANGE, 130 (3), pp.411-424. https:// doi.org/10.1007/s10584-014-1171-7.

Persistent Link:

http://hdl.handle.net/11343/282581 